\title{
DESIGN AND ANALYSIS OF MODIFIED CIRCULAR FRACTAL ANTENNA FOR S, C AND $\mathrm{X}-\mathrm{BAND}$ APPLICATIONS
}

\author{
Taniya \\ Department of ECE \\ M. Tech, Punjabi University Patiala
}

\begin{abstract}
In this paper, presenting the design and analysis of Modified Circular Fractal Antenna (MCFA) for S, C and $\mathrm{X}$ - band applications. Used the defined range of $\mathrm{S}$ band is $2 \mathrm{GHz}-4 \mathrm{GHz}, \mathrm{C}$-band is $4 \mathrm{GHz}-8 \mathrm{GHz}$ and $\mathrm{X}$-band is 8GHz-12GHz. S-band communication antennas have application in weather, tracking, and microwave oven. Cband antennas are useful in telecommunication, satellite communication and $\mathrm{X}$-band is useful in radar applications. The proposed antenna has been implanted on FR4-epoxy substrate with the dielectric constant of 4.4 and height of $1.6 \mathrm{~mm}$. Circular fractal antenna exhibits all required parameters that depends on the sizq and feed line position of the circular patch. The antenna has also been fabricated with optimized dimensions and then tested. The proposed antenna is fed by a microstrip line feed. The proposed antenna has been designed and simulated by HFSS vs 13.0 (High Frequency Structure Simulator). The various antenna parameters such as return loss, VSWR, gain and radiation pattern has been calculated. This proposed antenna operates at five different frequencies $2.87 \mathrm{GHz}$, $6.39 \mathrm{GHz}, 6.89 \mathrm{GHz}, 8.00 \mathrm{GHz}$ and $8.51 \mathrm{GHz}$. The vector Network Analyzer (VNA) of proposed antenna is used for the measurement of return loss, VSWR. The simulated and measured results are compared and are found to be a good relative values with each other. Small in size, reduction in construction costs are the advantages of proposed antenna.
\end{abstract}

Keywords- Circular fractal antenna, Circular slot, Microstrip line feed

\section{INTRODUCTION}

The microstrip antenna is a small and simple antenna consists of a radiating patch, substrate and a ground plane. Its patch shape can be arbitrary. It may be square, rectangular, conical, circular, triangular, star, pentagonal and hexagonal. The most popular shapes of patch are circle and rectangle. There are two degrees of freedom called length and width to control the rectangular patch and one degree of freedom radius to control for the circular patch [2]. The microstrip antenna can also find various applications on the surface of high performance aircraft, satellites, transmitters and mobile phones for which size, weight, space, cost and ease of installation on embedded system are the important factors [4]. Generally every antenna operates at single or in some cases on dual frequency bands. Different applications require different antennas which cause space limiting problem. So, we use a multiband antenna in which single antenna can operate at many frequency bands. This multiband antenna is designed by applying fractal shape into the antenna geometry for efficient use [5]. Benoit Mandelbrot were first defined the term Fractal which is derived from the Latin word fractus which means irregular fragments or broken. The pattern which is repeated at every iteration is term as Fractal. A fractal is a fragmented geometrical shape that can be subdivided in parts where each part is a reduced-size copy of the whole [5]. Reduced size multiband antenna can be developed by applying fractal concepts. The various properties of the fractal antenna are small scale, simple recursive processes, self -similarity, fractal dimension [6]. The main properties of fractal antenna are: space filling and self-similarity. The space filling property can be useful to design a small antennas such as Sierpinski Gasket. Its self-similar property can be useful to design multifrequency antennas like Sierpinksi Carpet. There are many mathematical structures that are fractals shapes such as Sierpinski's Gasket, von Koch's curve, Cantors comb [5]. The fractal applications can be found in various fields such as filter design, weather prediction, mobile devices, integrated circuits etc. The fractals have no characteristic size. These are generally composed of copies of themselves of different sizes [4]. The most popular amoung the manyavailable methods for analysis of antenna are transmission line model, full wave model and cavity model [2].

In this paper, a unique model of MCFA has been proposed. This paper is organized in sections as follows. The section II explains the antenna design and procedure. The section III describes antenna design. The section IV discussed the results. In section $\mathrm{V}$, a conclusion of different results is drawn.

\section{ANTENNA DESIGN AND PROCEDURE}

There are three basic calculating parameters operating frequency, dielectric constant and height of substrate that are to be decided for designing antennas. 


\section{International Journal of Engineering Applied Sciences and Technology, 2021 \\ Vol. 5, Issue 12, ISSN No. 2455-2143, Pages 169-175 \\ Published Online April 2021 in IJEAST (http://www.ijeast.com)}

Step I. Resonant frequency selection - The various wireless applications uses different operating frequency. The entire frequency band is furthur divided into different bands and each band has a unique frequency range with different applications.

Step II. Selection of substrate - This parameter decides the patch dimensions. FR-4 epoxy and Rogers RT Duroid5880 are the two most commonly used substrate [8]. The FR-4 epoxy has a dielectric constant of 4.4, Rogers RT Duroid 5880 and loss tangent of 0.02 has a dielectric constant of 2.2, loss tangent of 0.0009. Due to ease of availability, FR4 glass epoxy is used as substrate for the design of antenna.

Step III. Height of substrate - It is found that as substrate height increases, efficiency and bandwidth of antenna increases. This can make an antenna more bulky. So, The proposed antenna, design height of substrate $1.6 \mathrm{~mm}$ has been used.

Step IV. Calculate circular patch dimension -The radius of the circular patch can be calculated as from the following expression as in [1] by using a cavity model method. This model provides method that normalized fields between the patch and ground plane can be calculated more pecisely and does not radiate any power [2].

$$
\mathrm{a}=\frac{\mathrm{F}}{\left\{1+\frac{2 \mathrm{~h}}{\pi \hat{\mathbf{I}}_{\mathrm{r}} \mathbf{F}}\left[\ln \left(\frac{\pi \mathrm{F}}{2 \mathrm{~h}}\right)+1.7726\right]\right\}^{0.5}}
$$

Where,

$$
F=\frac{8.791 * 10^{9}}{\sqrt{\epsilon_{r}}}
$$

where $\mathrm{a}$ is the radius of the patch, $\mathrm{r}$ is the dielectric constant of the substrate, $h$ is the height of the substrate and $\mathrm{fr}$ is the resonant frequency.

Step V. Feed line selection - Five configurations microstrip line feed, coaxial feed, aperture coupled feed, proximate coupled feed and coplanar waveguide feed that can be used to feed microstrip antennas. Microstrip line feed and coaxial feed are the two most commonly used feeding techniques. The advantage of microstrip line feed is easy to fabricate, match by controlling the inset position simple to model.

Step VI. Fractal geometry iterations - The geometry of the fractal antenna encourages its study of a multiband solution and also for a small antenna [5]. Circular shape fractal geometry has been designed in this paper. Three iterations are performed in this paper.

\section{ANTENNA DESIGN}

Figure 1 expresses the generation process of the proposed MCFA.

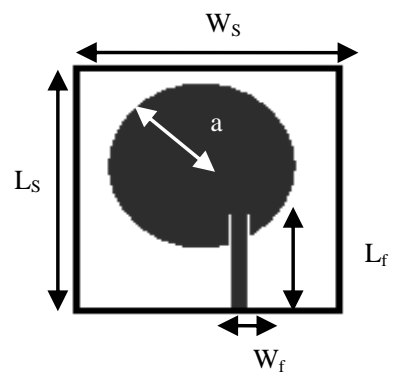

Fig. 1. (A) $0^{\text {TH }}$ ITERATION STAGE OF CirCULAR FraCtAL ANTENNA,

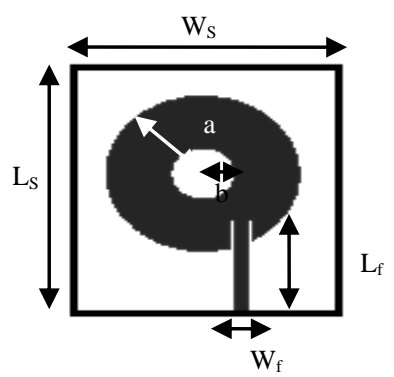

(B) IST ITERATION STAGE OF CIRCULAR FRACTAL ANTENNA

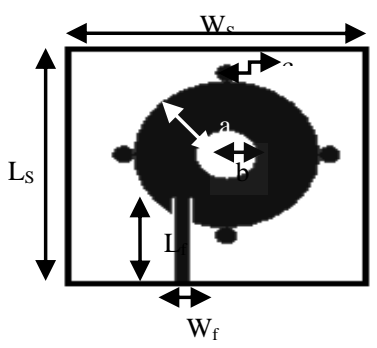

(C) IIND ITERATION STAGE OF CIRCULAR FRACTAL ANTENNA

The design of MCFA starts with single iteration using a circular using conductor as a ground dielectric substrate and base geometry. Various steps for the design of different iterations of MCFA are discussed as follows:

Step 1: Radius of circular geometry is calculated using equation (1) and this radius is found $12.6 \mathrm{~mm}$.

Step 2: A circle whose radius $(4.2 \mathrm{~mm})$ is $1 / 3 \mathrm{rd}$ of radius of base circular geometry is cut from the center of base geometry to get first iteration geometry as shown in Fig.1 (b).

Step 3: Four circles having radii 1/9th of the radius of base circular geometry are placed at the opposite edges of diameter of the first iteration geometry to get second iteration geometry as shown in Fig.1(c). 


\section{International Journal of Engineering Applied Sciences and Technology, 2021 \\ Vol. 5, Issue 12, ISSN No. 2455-2143, Pages 169-175 \\ Published Online April 2021 in IJEAST (http://www.ijeast.com)}

Table1. Dimensions of patch and substrate for the design of different iterations of MCFA

\begin{tabular}{|c|c|c|c|}
\hline \multicolumn{1}{|c|}{ Parameters (mm) } & $\begin{array}{c}\text { Oth } \\
\text { Iteration }\end{array}$ & $\begin{array}{c}\text { Ist } \\
\text { Iteration }\end{array}$ & $\begin{array}{c}\text { IInd } \\
\text { Iteration }\end{array}$ \\
\hline Length of substrate, Ls & 44.92 & 44.92 & 44.92 \\
\hline Width of substrate, Ws & 45 & 45 & 45 \\
\hline Radius of circular patch, a & 12.6 & 12.6 & 12.6 \\
\hline Length of feed line, Lf & 15 & 15 & 15 \\
\hline Width of feed line, Wf & 1.8 & 1.8 & 1.8 \\
\hline First iteration slot cut size ,b & - & 4.2 & - \\
\hline Second iteration slot, size, c & - & - & 1.4 \\
\hline
\end{tabular}

\section{RESULTS AND DISCUSSIONS}

Simulated Results of MCFA - In these results, different parameters of iterations of fractal geometry applied on patch are analised and compared. Figure 2 expresses the simulated return loss variation with frequency for MCFA. Return loss is related to both reflection coefficient $(\Gamma)$ and standing wave ratio (SWR). Decrease in the return loss corresponds to lower SWR. The return loss is a measure of good connection between the devices or lines. If the return loss is low then the match is good. Low return loss is desirable and results in lower insertion loss [1].

Simulated Results of MCFA - For these results, different iterations of fractal geometry applied on patch are then compared. Figure 2 explains the simulated return loss variation with frequency for MCFA. The return loss is related to both reflection coefficient $(\Gamma)$ and standing wave ratio (SWR). Decrease in the return loss corresponds to lower SWR. Return loss is a measure of how well the devices or lines are matched [1].

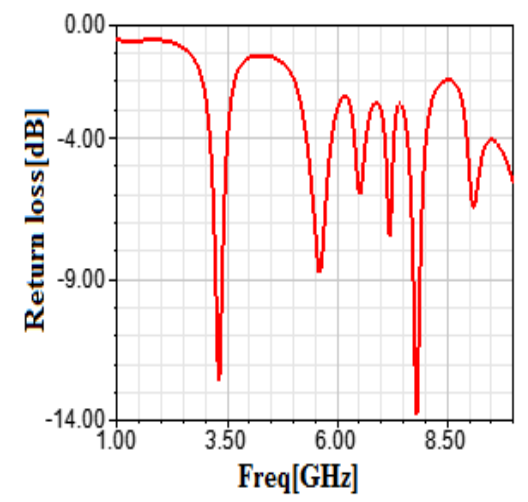

Fig. 2. Simulated return loss vs. frequency plot of (a) $0^{\text {th }}$ iteration stage,

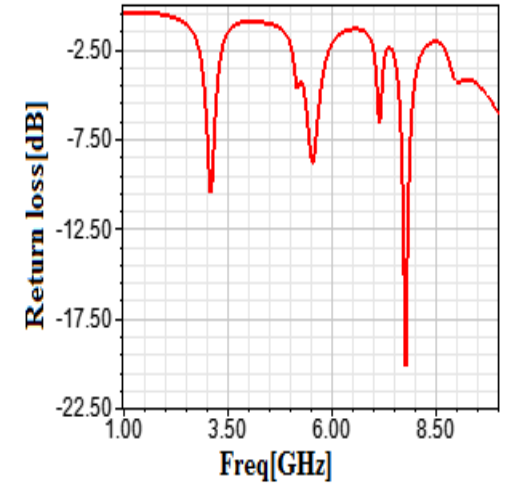

(b) Ist iteration stage,

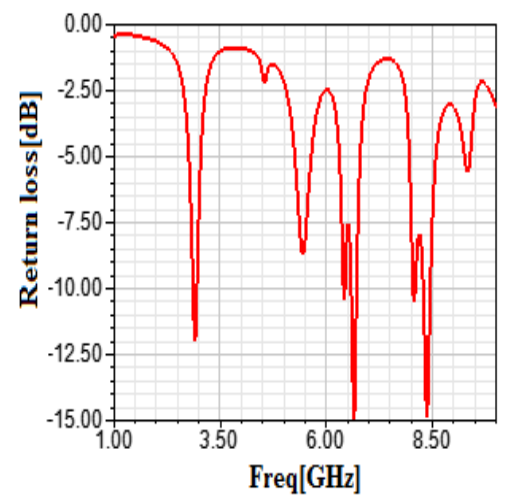

(c) IInd iteration stage

One of the most important parameter is VSWR (voltage standing wave ratio). Increase in VSWR indicates a increase in the mismatch between antenna and transmission line and decrease in VSWR means good matching with minimum VSWR is one. The simulated results of VSWR shown as in figure 3. Most wireless system operates at $50 \mathrm{ohm}$ impedance [5].

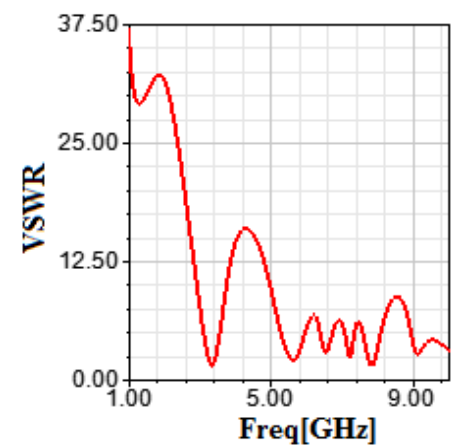

Figure 3. Simulated VSWR of (a) 0th iteration stage, 
International Journal of Engineering Applied Sciences and Technology, 2021

Vol. 5, Issue 12, ISSN No. 2455-2143, Pages 169-175

Published Online April 2021 in IJEAST (http://www.ijeast.com)

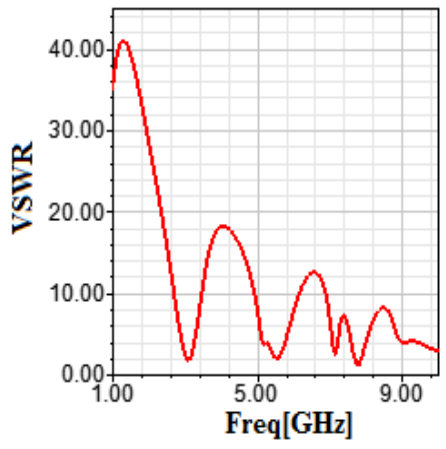

(b) Ist iteration stage

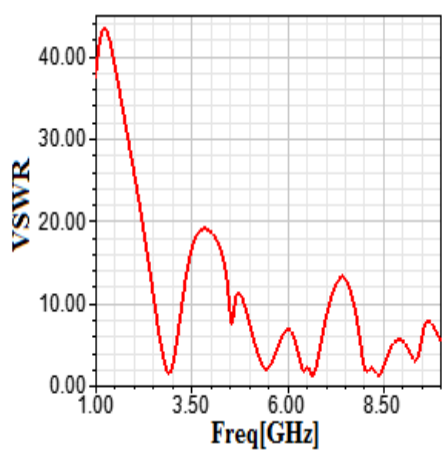

(c) IInd iteration stage fabrication tolerances and measurement accuracy. Simulated radiation patterns of proposed antenna for $0^{\text {th }}$, Ist and IInd iteration geometry are shown in Figure 4, Figure 5 and Figure 6 respectively.
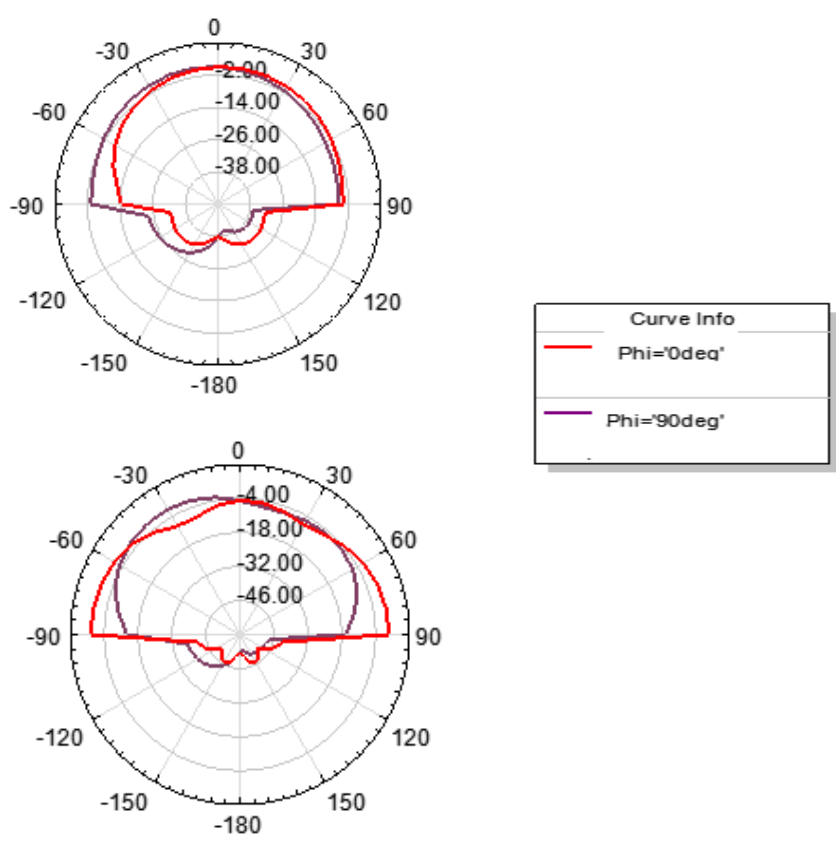

Figure 4. Simulated radiation pattern of Oth iteration at (a) $3.34 \mathrm{GHz}$ (b) $7.81 \mathrm{GHz}$

Table2. Simulated performance parameters of $0^{\text {th }}$, Ist and IInd iteration

\begin{tabular}{|l|c|c|c|c|c|}
\hline \multirow{3}{*}{$\begin{array}{l}\text { Iteration } \\
\text { Number }\end{array}$} & \multicolumn{5}{|c|}{ Simulated Results } \\
\cline { 2 - 6 } & $\begin{array}{c}\text { Resonance } \\
\text { Frequency } \\
(\mathrm{GHz})\end{array}$ & $\begin{array}{c}\text { Return } \\
\text { Loss } \\
(\mathrm{dB})\end{array}$ & $\begin{array}{c}\text { Gain } \\
(\mathrm{dB})\end{array}$ & VSWR & $\begin{array}{c}\text { Bandwidth } \\
(\mathrm{MHz})\end{array}$ \\
\hline Oth iteration & 3.34 & -12.54 & 1.48 & 1.61 & 28.1 \\
\cline { 2 - 7 } & 7.81 & -13.71 & 1.82 & 1.51 & 47.2 \\
\hline Ist iteration & 3.10 & -10.49 & 2.18 & 1.85 & 5.1 \\
\cline { 2 - 7 } & 7.76 & -20.05 & 2.90 & 1.22 & 43.5 \\
\hline IInd & 2.91 & -11.96 & 3.34 & 1.67 & 6.2 \\
\cline { 2 - 7 } & 6.42 & -10.40 & 3.60 & 1.86 & 11.2 \\
\cline { 2 - 7 } & 6.65 & -14.93 & 8.87 & 1.43 & 41.3 \\
\cline { 2 - 7 } & 8.06 & -10.48 & 4.33 & 1.85 & 52.6 \\
\cline { 2 - 7 } & 8.36 & -14.83 & 7.45 & 1.44 & 30.9 \\
\hline
\end{tabular}

Radiation pattern is another important parameter. An antenna radiation pattern is defined as a graphical representation or a mathematical function of the radiation properties of the antenna as a function of space coordinates expressed in $\mathrm{dB}$ [2]. There is some difference between simulated and experimental value which occurs due to

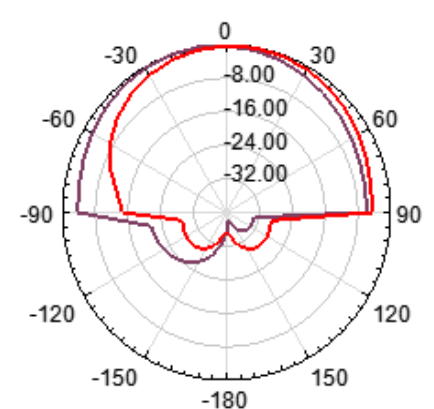

(a)
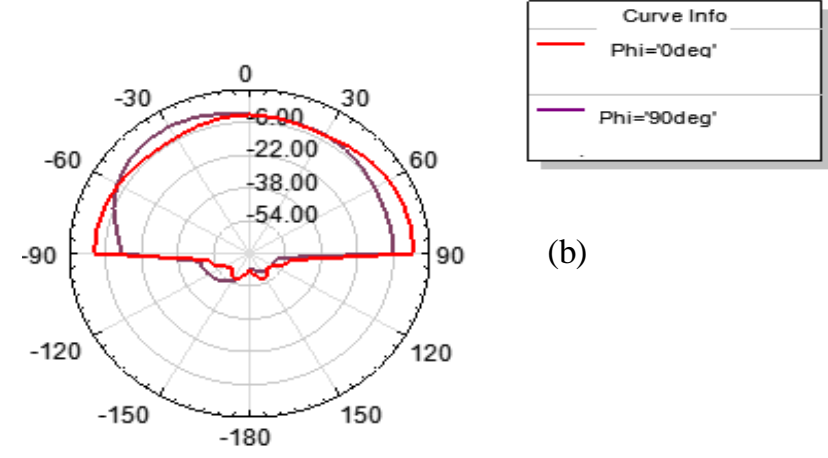

(b) 


\section{International Journal of Engineering Applied Sciences and Technology, 2021 \\ Vol. 5, Issue 12, ISSN No. 2455-2143, Pages 169-175 \\ Published Online April 2021 in IJEAST (http://www.ijeast.com)}

Fig. 5. Simulated radiation pattern of Ist iteration at (a) $3.10 \mathrm{GHz}$ (b) $7.76 \mathrm{GHz}$

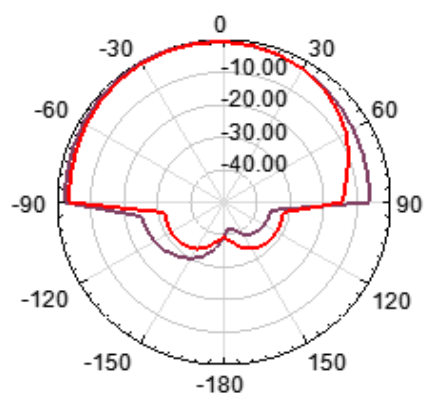

(e)

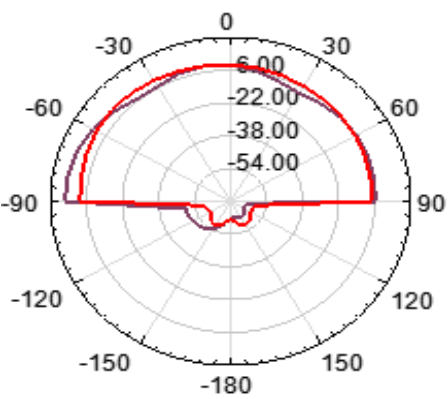

(a)

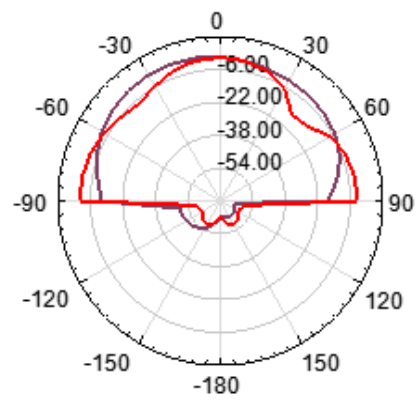

(b)

(c)

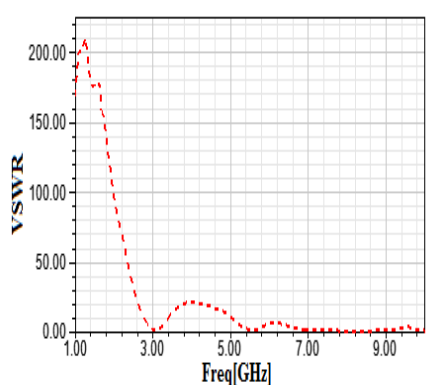

(d)
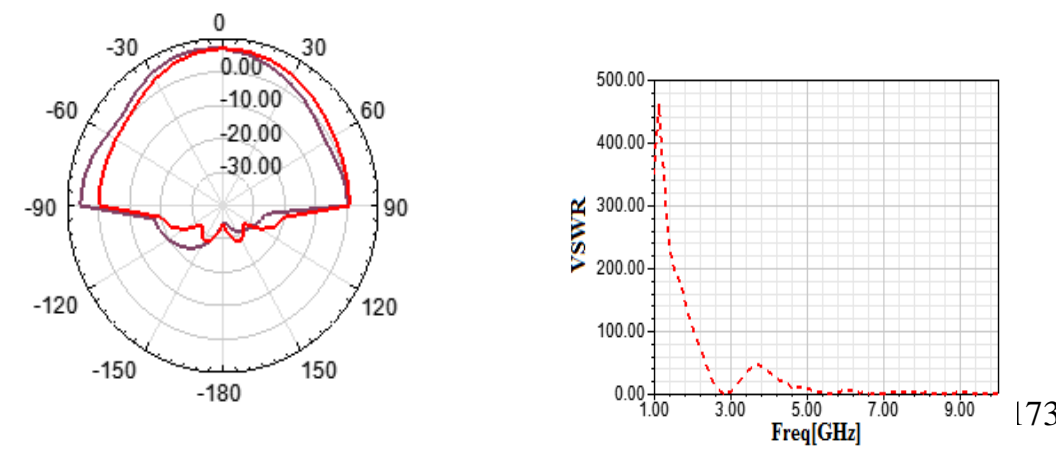

Fig. 6. Simulated radiation pattern of IInd iteration at (a) $2.91 \mathrm{GHz}$ (b) $6.42 \mathrm{GHz}$ (c) $6.65 \mathrm{GHz}$ (d) $8.06 \mathrm{GHz}$ (e) $8.36 \mathrm{GHz}$

The optimized design parameters of the proposed antenna configurations are used for the fabrication of the antenna. The fabricated zeroth, first and second iterations of proposed antenna are shown in figure 7 .

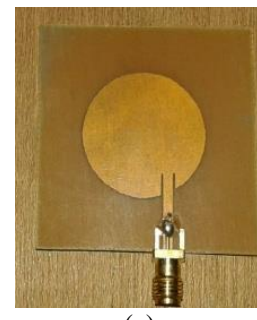

(a)

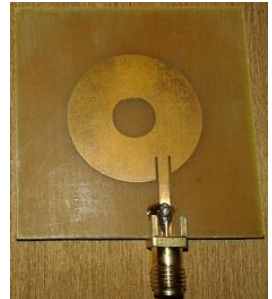

(b)

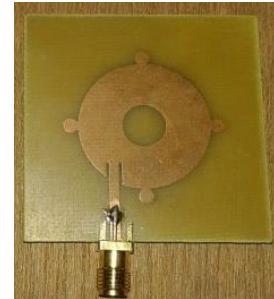

(c)
Fig. 7. Fabricated geometry of (a) 0th iteration (b) Ist iteration (c) IInd iteration

Vector Network Analyzer was used to measure the electrical performance of the proposed antenna such as return loss, VSWR. The measurements are carried out using VNA Anritsu (MS46322A, 20GHz). Measured results of MCFA - Fig 8 shows the measured return loss variation frequency of 0 th, Ist and IInd iteration of MCFA.

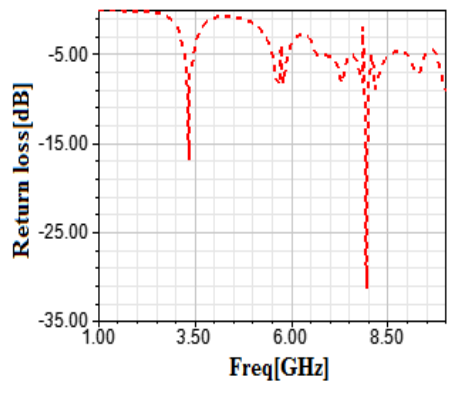

(a) (c) 


\section{International Journal of Engineering Applied Sciences and Technology, 2021 \\ Vol. 5, Issue 12, ISSN No. 2455-2143, Pages 169-175 \\ Published Online April 2021 in IJEAST (http://www.ijeast.com)}

Fig. 8. Measured return loss vs. frequency plot (a) $0^{\text {th }}$ iteration (b) Ist iteration (c) IInd iteration

Figure 9 shows the measured VSWR of 0th, Ist and IInd iteration of MCFA.

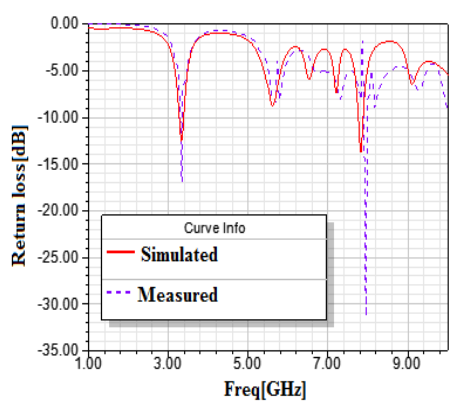

(a)

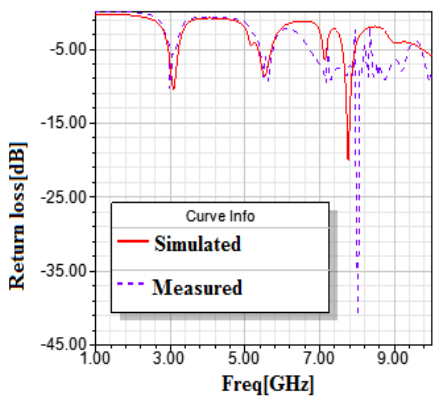

(b)

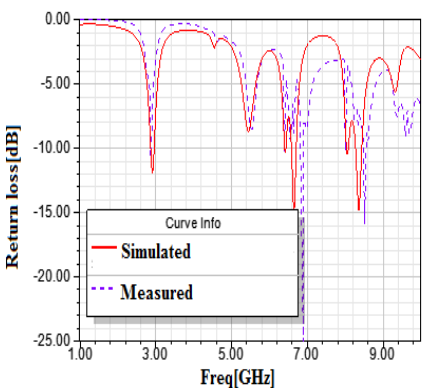

(c)

Fig. 9. Simulated and measured return loss vs. frequency plot of (a) $0^{\text {th }}$ iteration (b) Ist iteration (c) IInd iteration
Table 3. Simulated performance parameters of $0^{\text {th }}$, Ist and IInd iteration

\begin{tabular}{|c|c|c|c|c|c|}
\hline \multirow{2}{*}{$\begin{array}{l}\text { Iteration } \\
\text { Number }\end{array}$} & \multicolumn{5}{|c|}{ Simulated Results } \\
\hline & $\begin{array}{c}\text { Resonanc } \\
\mathrm{e} \\
\text { Frequenc } \\
\mathrm{y} \\
(\mathrm{GHz})\end{array}$ & $\begin{array}{c}\text { Return Loss } \\
\text { (dB) }\end{array}$ & $\begin{array}{l}\text { Gain } \\
\text { (dB) }\end{array}$ & VSWR & $\begin{array}{c}\text { Bandwidt } \\
\mathrm{h} \\
(\mathrm{MHz})\end{array}$ \\
\hline \multirow{2}{*}{$\begin{array}{l}0^{\text {th }} \\
\text { iteration }\end{array}$} & 3.34 & -12.54 & 1.48 & 1.61 & 28.1 \\
\hline & 7.81 & -13.71 & 1.82 & 1.51 & 47.2 \\
\hline \multirow{2}{*}{$\begin{array}{l}\text { Ist } \\
\text { iteration }\end{array}$} & 3.10 & -10.49 & 2.18 & 1.85 & 5.1 \\
\hline & 7.76 & -20.05 & 2.90 & 1.22 & 43.5 \\
\hline \multirow{5}{*}{$\begin{array}{l}\text { IInd } \\
\text { iteration }\end{array}$} & 2.91 & -11.96 & 3.34 & 1.67 & 6.2 \\
\hline & 6.42 & -10.40 & 3.60 & 1.86 & 11.2 \\
\hline & 6.65 & -14.93 & 8.87 & 1.43 & 41.3 \\
\hline & 8.06 & -10.48 & 4.33 & 1.85 & 52.6 \\
\hline & 8.36 & -14.83 & 7.45 & 1.44 & 30.9 \\
\hline
\end{tabular}

Table 4. Measured performance parameters of $0^{\text {th }}$, Ist and IInd iteration

\begin{tabular}{|c|c|c|c|c|}
\hline \multirow{2}{*}{$\begin{array}{l}\text { Iteration } \\
\text { Number }\end{array}$} & \multicolumn{4}{|c|}{ Measured Results } \\
\hline & $\begin{array}{c}\text { Resonance } \\
\text { Frequency } \\
(\mathrm{GHz})\end{array}$ & $\begin{array}{c}\text { Return Loss } \\
\text { (dB) }\end{array}$ & VSWR & $\begin{array}{c}\text { Bandwidth } \\
(\mathrm{MHz})\end{array}$ \\
\hline \multirow[t]{2}{*}{$0^{\text {th }}$ iteration } & 3.34 & -16.90 & 1.40 & 40 \\
\hline & 7.93 & -31.30 & 1.64 & 90 \\
\hline \multirow[t]{2}{*}{ Ist iteration } & 3.00 & -10.40 & 1.60 & 10 \\
\hline & 8.02 & -41.10 & 1.01 & 120 \\
\hline \multirow{5}{*}{$\begin{array}{l}\text { IInd } \\
\text { iteration }\end{array}$} & 2.87 & -11.50 & 1.09 & 20 \\
\hline & 6.39 & -10.30 & 1.49 & 10 \\
\hline & 6.89 & -25.00 & 1.75 & 80 \\
\hline & 8.00 & -10.30 & 1.33 & 10 \\
\hline & 8.51 & -15.90 & 1.39 & 80 \\
\hline
\end{tabular}

\section{CONCLUSION}

In this paper, a modified circular fractal antenna with three iterations is designed, analysed and simulated. A detailed description about the design and the fabrication process has been presented. From Table III, it is clear that resonant frequency of proposed antenna is decreased from $3.34 \mathrm{GHz}$ to $2.91 \mathrm{GHz}$ as the iteration number is increased from 0th to IInd iteration. Thus miniaturization of MCFA is taking place. The proposed antenna shows omni-directional 
radiation pattern in $\mathrm{H}$ plane. Similairly shows symmetric pattern in E plane at all operating frequencies.

\section{REFERENCE}

[1] Balani C.A. (1997), Antenna Theory: Analysis and Design, IInd Ed, John Wiley \& Sons, Inc, New York.

[2] Varadhan Chitra, Pakkathillam Jayaram Kizhekke, Kanagasabai Malathi, Sivasamy Ramprabhu, (2003), Triband antenna structures for RFID systems deploying fractal geometry, IEEE Antennas Wireless Propag. Lett., vol.12, (pp.437-440).

[3] Werner D.H. and Ganguly Suman, (2013), An overview of fractal antenna engineering research, IEEE Antennas Propag. Mag., vol. 45,no. 1, (pp.38-57).

[4] Esther Florence Sundarsingh, SangeethaVelan, Malathi Kanagasabai, Aswathy K.Sarma, Chinnambeti Raviteja, and M. Gulam Nabi Alsath, (2011), Polygon-shaped slotted dual-band antenna for wearable applications, IEEE Antennas Wireless Propag. Lett., vol.13, (pp.611-614).

[5] Abraham Jacob and Thomaskutty Mathew, (2014), David Fractal Antenna for Multiband Wireless Communication, IEEE IInd International Conference on Electronic Design (ICED), (pp.15-19).

[6] Venkatachalapathi, Rao P.H., Sameer,Krishnasamy Selvan, (2015), Fractal slot coupled stacked microstrip antenna, IEEE Applied Electromagnetic conferences (AEMC), (pp.1-2).

[7] Kushwaha Nagendra, Kumar Raj, (2010), On design of UWB slot circular fractal antenna for wireless applications, IEEE Applied Electromagnetic conferences, (pp.1-2).

[8] Jothilakshmi, (2016), Circular patch with star triangular fractal antenna for SWB applications, IEEE International Conference on Communication and Signal Processing, (pp.485-489).

[9] Choudhary Ruchika, Yadav Sanjeev, Jain Pushpanjali, Sharma M.M (2012), Full composite fractal antenna with dual band used for wireless applications, IEEE International Conference on Advances in Computing, Communication and Informatics, (pp-2517-2520).

[10] Velan Sangeetha, Esther Florence Sundar singh, Malathi Kanagasabai, Member, IEEE, Aswathy K.Sarma, Chinnambeti Raviteja, Ramprabhu Sivasamy and Jayaram Kizhekke Pakkathillam, (2014), Dual -band EBG Integrated Monopole Antenna Deploying Fractal Geometry for wearable applications, IEEE Antenna Wireless Propag. Lett, vol. 14, (pp-249-252).

[11] Yadav Sanjeev, Choudhary Ruchika, Soni Umesh, Dadhich Ajay, Mahendra Mohan Sharma, (2008), A Dual band star fractal antenna with slot for wireless applications, IEEE International Conference on Signal
Propagation and Computer Technology (ICSPCT), (pp738-740).

[12] Sudha T, Sreerag M, (2016), A Hexagonal boundary fractal antenna with WiMAX band rejection, IEEE National Conference on Communication, Signal Processing and Networking, (pp. 1-4). 